\title{
Experience in a Public Cord Blood Bank Using a Segment-Based Aldehyde Dehydrogenase Assay as a Biomarker for Umbilical Cord Blood Potency
}

\author{
KeVin Shoulars, ${ }^{a, b, c}$ Ann Kaestner, ${ }^{c}$ Melissa McCarthy, ${ }^{c}$ Lisa Eddinger, ${ }^{c}$ JoAnNe Kurtzberg ${ }^{a, b, c}$
}

${ }^{a}$ Duke University Medical Center, Durham, North Carolina, USA; ${ }^{\mathrm{b}}$ Marcus Center for Cellular Cures, Duke University School of Medicine, Durham, North Carolina, USA; 'Carolinas Cord Blood Bank, Duke University Medical Center, Durham, North

Carolina, USA

\section{ABSTRACT 5}

\section{Introduction}

Cryopreserved cord blood units (CBU) provide a source of hematopoietic stem cells for transplantation for patients in need of a suitable donor. Primary graft failures and delayed engraftment occur in $10 \%-15 \%$ of patients following cord blood (CB) transplant, which may be due to low potency, defined as low levels of engrafting hematopoietic stem and progenitor cells. Transplant centers select CBUs based on HLA match, pre-cryopreservation total nucleated cell count, and occasionally, viable $\mathrm{CD}_{3} 4^{+}$content. These methods do not account for potential insults during cryopreservation and thawing that affects the overall potency.

\section{Objectives}

Preliminary studies showed that post-thaw hematopoietic colony forming units (CFU) measured on the transplanted product reflect potency and predict engraftment and survival. However, post-thaw CFUs are not available at the time of CBU selection or transplantation due to lengthy assay times (14 days). CFUs measured on fresh CB correlate with the number of cells expressing high levels of the enzyme aldehyde dehydrogenase $\left(\mathrm{ALDH}^{\mathrm{br}}\right)$. Retrospective studies indicated that $\mathrm{ALDH}^{\mathrm{br}}$ content could be a biomarker for potency, as $\mathrm{ALDH}^{\mathrm{br}}$ content of segments associated with transplanted CBUs correlated with engraftment.

\section{Methods}

We developed a rapid ALDH-based potency assay in CBU attached segments that could be performed when HLA confirmatory typing was requested. From March 2010 to May 2018, segments from CBUs were analyzed $(n=6,128)$. The number of viable (7-AAD-) $, \mathrm{CD}^{\circ} 5^{+}, \mathrm{ALDH}^{\mathrm{br}}$, and $\mathrm{CD} 34^{+}$cells were measured by flow cytometry using multiparameter gating with samples plated for CFU quantitation.

\section{Results}

The percentage of $\mathrm{ALDH}^{\text {br }}$ (Spearman rho $=0.81$ ) correlated well with CFU frequency. In contrast, CFU correlated less well with viable $\mathrm{CD}^{+} 4^{+}(r=0.30)$. These observations were valid regardless of time in cryostorage.

\section{Discussion}

These results suggest the $\mathrm{ALDH}^{\mathrm{br}}$ segment assay is a reliable surrogate potency assay for the lengthier CFU measurement. This potency assay has been validated and approved by the U.S. Food and Drug Administration for incorporation into the Biologics License Application (BLA) of the Carolinas Cord Blood Bank. In addition, the assay has been transferred out of the research laboratory and into the cord blood bank processing laboratory to be used as a routine part of testing for rapid selection and release of $\mathrm{CBUs}$ to the transplant centers. 